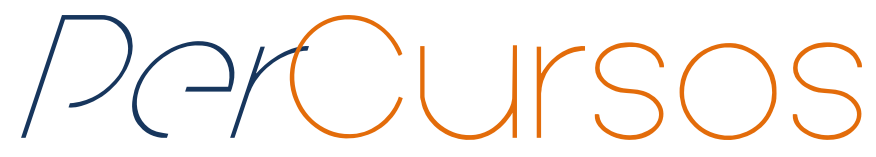

\title{
Cartografia de queimadas e incêndios aplicados à mitigação de desastres e conservação de paisagens
}

\begin{abstract}
Resumo
Este estudo teve como objetivo desenvolver uma cartografia de susceptibilidade à ocorrência de queimadas e incêndios municipal, a partir da integração de dados geoespaciais representativos, com o estabelecimento de coeficientes e pesos adaptados às características socioambientais do objeto de estudo trabalhado, o município de Santa Teresa (ES). A validação do produto tomou como referência os registros de focos de calor disponibilizados junto ao Banco de Dados de Queimadas do Instituto Nacional de Pesquisas Espaciais entre os anos de 2007 a 2017. Os resultados revelaram que dos 50 focos detectados, 31 deles ocorreram em locais de alta susceptibilidade a incêndios da cartografia modelada, correspondendo a $62 \%$ dos registros que cobrem apenas $27,1 \%$ do território. Já a análise mensal indicou os maiores registros nos meses marcados por baixos índices pluviométricos e secos, entre abril e outubro, concentrando $68 \%$ das ocorrências. O emprego desta metodologia apresenta uma importante contribuição para ações de controle e monitoramento e ação preventiva possível de ser aplicada em municípios ou regiões carentes de estudos dessa natureza.
\end{abstract}

Palavras-chave: Sensoriamento remoto. SIG. Análise integrada. Focos de calor. Banco de dados de queimadas.

\section{André Luiz Nascentes Coelho}

Doutor em Geografia pela Univ.

Federal Fluminense - UFF.

Professor da Universidade

Federal do Espírito Santo - UFES. Brasil

alnc.ufes@gmail.com

\section{Antônio Celso de Oliveira Goulart}

Doutor em Geografia (Geografia Física) pela Universidade de São

Paulo - USP. Professor da

Universidade Federal do Espírito Santo - UFES.

Brasil

celsoliveiragoulart@gmail.com

\section{Para citar este artigo:}

COELHO, André Luiz Nascentes; GOULART, Antônio Celso de Oliveira. Cartografia de queimadas e incêndios aplicados à mitigação de desastres e conservação de paisagens. Revista PerCursos, Florianópolis, v. 20, n.43, p. 66 - 90, maio/ago. 2019.

\section{DOI: $10.5965 / 1984724620432019066$}

http://dx.doi.org/10.5965/1984724620432019066 


\title{
Cartography of fire applied to disaster mitigation and landscape conservation
}

\begin{abstract}
The objective of this study was to develop a cartography of susceptibility to the occurrence of municipal fires / burn, based on the integration of geospatial data with the establishment of coefficients and weights adapted to the socioenvironmental characteristics of the study object in the city of Santa Teresa, state of Espírito Santo - Brazil. The validation of the product took as reference the records of heat sources available at the Burning Database of the National Institute of Space Research between 2007 and 2017. The results revealed that of the 50 detected heat spotlights, 31 occurred in high places susceptibility to fires of the modeled cartography, corresponding to $62 \%$ of the records they cover, only $27.1 \%$ of the territory. Already monthly analysis indicated the highest records in the months marked by low rainfall and dry indexes, between april and october, concentrating 68\% of occurrences. The use of this methodology presents an important contribution to actions of control and monitoring / preventive action possible to be applied in municipalities or regions needy such studies.
\end{abstract}

Keywords: Remote sensing. GIS. Integrated analysis. Heat spotlights. Database of burns. 


\section{Introdução}

Em um rápido exame da situação atual da sociedade frente aos processos potencialmente danosos, verifica-se que foram poucos os avanços alcançados na redução das susceptibilidades aos desastres, mesmo àqueles de natureza cíclica. Os incêndios florestais e a perda de controle de queimadas ${ }^{1}$ se configuram em desastres humanos de natureza social resultantes de desequilíbrios provocados por ações ou por omissões sobre os ecossistemas urbanos e rurais (CANZIAN, 2016; SECRETARIA NACIONAL DE PROTEÇÃO E DEFESA CIVIL, 2003), definição que associa a ocorrência dessa modalidade de ameaça como um desastre natural climatológico pela Classificação e Codificação Brasileira de Desastres (Brasil, 2016). A essa condição se soma o efeito da localização das florestas que, muitas vezes, mostram-se consoantes com zonas potenciais de alta susceptibilidade climatológica, caracterizadas pela estiagem sazonal prolongada, aumentando assim o grau de risco a esse tipo de evento.

Há uma importante interação entre desenvolvimento rural, proteção ambiental e redução de risco de desastre que ratifica a importância no processo de planejamento territorial da prevenção dos desastres, a ser contemplado de maneira clara e permanente ao longo de todo o processo do desenvolvimento. Os efeitos desses fatos estão enfaticamente presentes nos dias atuais.

De acordo com o relatório da consultoria de gerenciamento de riscos AON BENFIELD (2018), a Europa em 2017 registrou, via satélite, a maior extensão de terras queimadas desde 1980. Foi o primeiro registro de mais de um milhão de hectares de terras queimadas em toda a Europa, sendo que o país mais afetado foi Portugal onde dois

\footnotetext{
${ }^{1}$ As expressões "Incêndios" e "Queimadas" são muitas vezes empregadas de maneira incerta em relação à sua origem e a seu contexto de ocorrência. Os incêndios, segundo a Classificação e Codificação Brasileira de Desastres - COBRADE (Brasil, 2016), são considerados um desastre natural climatológico pois, em grande parte das vezes, estão associados ao ambiente florestal, como é o caso de incêndio em bioma de cerrado. Os incêndios podem também ser de natureza acidental, indesejados e de difícil controle (VALLEJO, 2012 e KAZMIERCZAK, 2015). As queimadas, por sua vez, são consideradas práticas tradicionais controladas e estão associadas à cultura indígena, como também na agricultura, destinada principalmente à limpeza de parcelas para combater pragas e cultivo de plantações ou na formação de pastos. Porém, quando fogem do controle, podem transformar-se em incêndios (KAZMIERCZAK, 2015; VALLEJO, 2012). Neste trabalho, essas expressões serão tratadas de maneira conjugada, a partir da análise geográfica integrada, apontando as áreas mais susceptíveis à incidência de focos provocados por incêndios e queimadas.
} 
grandes incêndios, em junho e outubro, causaram 111 mortes. As perdas econômicas causadas por esses eventos totalizaram quase um bilhão de dólares, o desastre natural mais caro na história do país, com o fogo atingindo a $6,1 \%$ do território nacional português.

Essa mesma agência aponta ainda que, nesse ano de 2017, dois grandes incêndios na Califórnia, em outubro e em dezembro, levaram à destruição de mais de 10 mil construções em torno da região do Vale de Napa, com perdas econômicas totais superiores a 15 bilhões de dólares. Tanto em um quanto em outro caso, os fortes ventos e as condições prolongadas de seca estão entre as principais causas dos incêndios.

Essa tendência de resposta à condição climática local resultou da interação da localização no caminho dos fortes ventos, do aumento das temperaturas e das secas prolongadas, com estratégias ineficazes em mitigação de incêndios em silvicultura de eucaliptos que, apesar de sua importância para a indústria local, são considerados altamente inflamáveis.

O El Niño / Oscilação Sul (ENOS), ciclo que se refere aos períodos de aquecimento incomum das águas superficiais do Oceano Pacífico, tem a referência para determinar as fases/ciclos ENOS no índice Niño 3.4 que mede a temperatura das águas oceânicas no Pacífico Central. De acordo com os dados do Centro de Previsão Climática Nacional (CPC) da Administração Oceânica e Atmosférica Nacional (NOAA) - dos Estados Unidos, 2017 foi um ano inicialmente marcado por condições neutras de ENOS sendo que na maior parte do ano houve anomalias de temperatura da superfície do mar no Oceano Pacífico Equatorial, permanecendo entre $-0,5^{\circ} \mathrm{Ce}+0,5^{\circ} \mathrm{C}$ (CLIMATE PREDICTION CENTER, 2018).

No Brasil, de acordo com Mendonça e Danni-Oliveira (2007), o evento ENOS não é causador de grandes transformações do comportamento climatológico na região sudeste. Ao contrário, as demais regiões do país demonstram variações significativas nos totais de precipitação. Na região sudeste merece destaque o período correspondente ao inverno que, durante o ciclo ENOS, revela um ligeiro aumento da temperatura. As estiagens com redução das precipitações pluviométricas e atraso dos períodos chuvosos, 
quando ocorrem associadas ao ciclo ENOS, concorrem para o comprometimento das reservas hidrológicas locais e causam prejuízos à agricultura e à pecuária.

O baixo risco natural a incêndio florestal, neste caso, não equivale, necessariamente, a risco nenhum e, portanto, essa condição, se a princípio não causa alarme às condições climáticas locais no SE do Brasil, em geral, e ao Espírito Santo, em particular, serve de alerta para condições conjunturais que respondem por contingências importantes como a coincidência do período mais seco do ano na região e elevação da temperatura do ar na baixa atmosfera. As ondas de calor podem incrementar a queda sustentada da umidade atmosférica e favorecer a intensificação de incêndios florestais, principalmente porque os reflorestamentos (silvicultura) são realizados com coníferas, situação que amplifica a susceptibilidade florestal ao ressecamento e a sua predisposição à combustão.

O incêndio tem importância ambiental/ecológica fundamental ao exercer influência sobre o aumento da poluição atmosférica, na perda de biodiversidade, na alteração do padrão topoclimático e nos impactos diretos e indiretos, tais como empobrecimento do solo, desencadeamento de processos erosivos, problemas de saúde pública, prejuízos econômicos e sociais em diversas escalas, tanto local, em uma parcela de terra, quanto em escala global, a exemplo da emissão de $\mathrm{CO}^{2}$ na atmosfera (JENSEN, 2009).

Existem diversos métodos de monitoramento de incêndios que variam de acordo com as características do local, estrutura/logística, extensão da área manejada como as florestas através de postos de vigilância terrestres e/ou torres de observação, pelo patrulhamento por veículos, sobrevôos de avião/helicópteros e do uso de drones/vants, ações essas que são pontuais e de elevados custos econômicos, sobretudo, para órgãos públicos como prefeituras/governos. O uso das ferramentas computacionais como os Sistemas de Informações Geográficas (SIGs) integrados com produtos acessíveis e técnicas de Sensoriamento Remoto (SR) são, na atualidade, uma alternativa eficiente, de baixo custo, que oferece uma ampla visão sobre a distribuição temporal e espacial desse fenômeno, em diferentes escalas, permitindo analisar as interações do fogo relacionado com fatores culturais e socioambientais. 
Nessa perspectiva, os SIGs e os produtos de SR têm sido responsáveis por uma importante evolução nas técnicas de análise espacial, notadamente nos estudos ambientais, propiciando expressivos avanços na obtenção de dados, tratamento e geração de informações da cobertura terrestre e marinha (COELHO, 2017; KAZMIERCZAK, 2015; ROSS, 2009).

A esse propósito, Coelho (2013) argumenta que o emprego das ferramentas SIG e SR deve ser efetuado, preferencialmente, por um especialista, de maneira prudente. Considerada como instrumento de apoio e não de decisão nas diversas modalidades de aplicação, como a geração de modelos que apontam áreas susceptíveis a desastres, que necessita, após a elaboração da cartografia, ser comprovado e aprovado com base em estudos pontuais e/ou campanhas de campo viabilizando, assim, o tratamento mais eficiente do problema.

Sustentado nesses conceitos e realidades, torna-se importante compreender a variação espacial e sazonal da ocorrência das queimadas e dos incêndios em um recorte espacial, por intermédio da proposição de um produto síntese, de eficiente comunicação e compreensão no sentido de estabelecer ações de monitoramento, controle, combate, recuperação de paisagens incluindo, também, orientações de prática de queimadas controladas, evitando a causa de incêndios.

Nessa linha de discussão, este trabalho tem como objetivo colocar em evidência a importância do desenvolvimento da cartografia de susceptibilidade a queimadas e incêndios aplicada na redução dos riscos causados por esse fenômeno e aumento da resiliência das paisagens no município de Santa Teresa (ES) e nas Unidades de Conservação presentes no seu território. Busca-se, também, responder às seguintes indagações: 1) É possível elaborar uma cartografia de susceptibilidade eficiente voltada à gestão de incêndios florestais no município a partir de um conjunto representativo de dados geoespaciais acessíveis, integrados em ambiente SIG? 2) A cartografia proposta é condizente com os focos de calor (incêndios e/ou queimadas) detectados por satélites no município? 3) Qual a susceptibilidade a incêndios nas Unidades de Conservação que estão presentes no território? 
Os objetivos específicos são: utilizar dados e informações gratuitas; destacar as principais etapas da modelagem; verificar, por intermédio de registros, a viabilidade e eficiência do mapa de queimadas e incêndios; difundir e aperfeiçoar o uso integrado e a aplicação das geotecnologias de baixo custo referentes aos produtos de sensoriamento remoto e dos sistemas de informações geográficas em pesquisas e no auxílio na tomada de decisões buscando a prevenção e resiliência.

\section{Caracterização do objeto de estudo}

O município de Santa Teresa-ES (Figura 1), objeto deste estudo, situa-se na Microrregião Central Serrana com sua sede distante 83,4 km da capital Vitória. Conta com uma área de 683,11 km² e cerca de 23.392 habitantes, de acordo com a estimativa populacional publicada em 2018 pelo Instituto Brasileiro de Geografia e Estatística (INSTITUTO BRASILEIRO DE GEOGRAFIA E ESTATÍ́STICA, 2018).

Figura 1 - Imagem satélite Resourcesat-2 fusionada com o Modelo Digital de Elevação (MDE) destacando o Município, os Corredores Ecológicos e as Unidades de Conservação

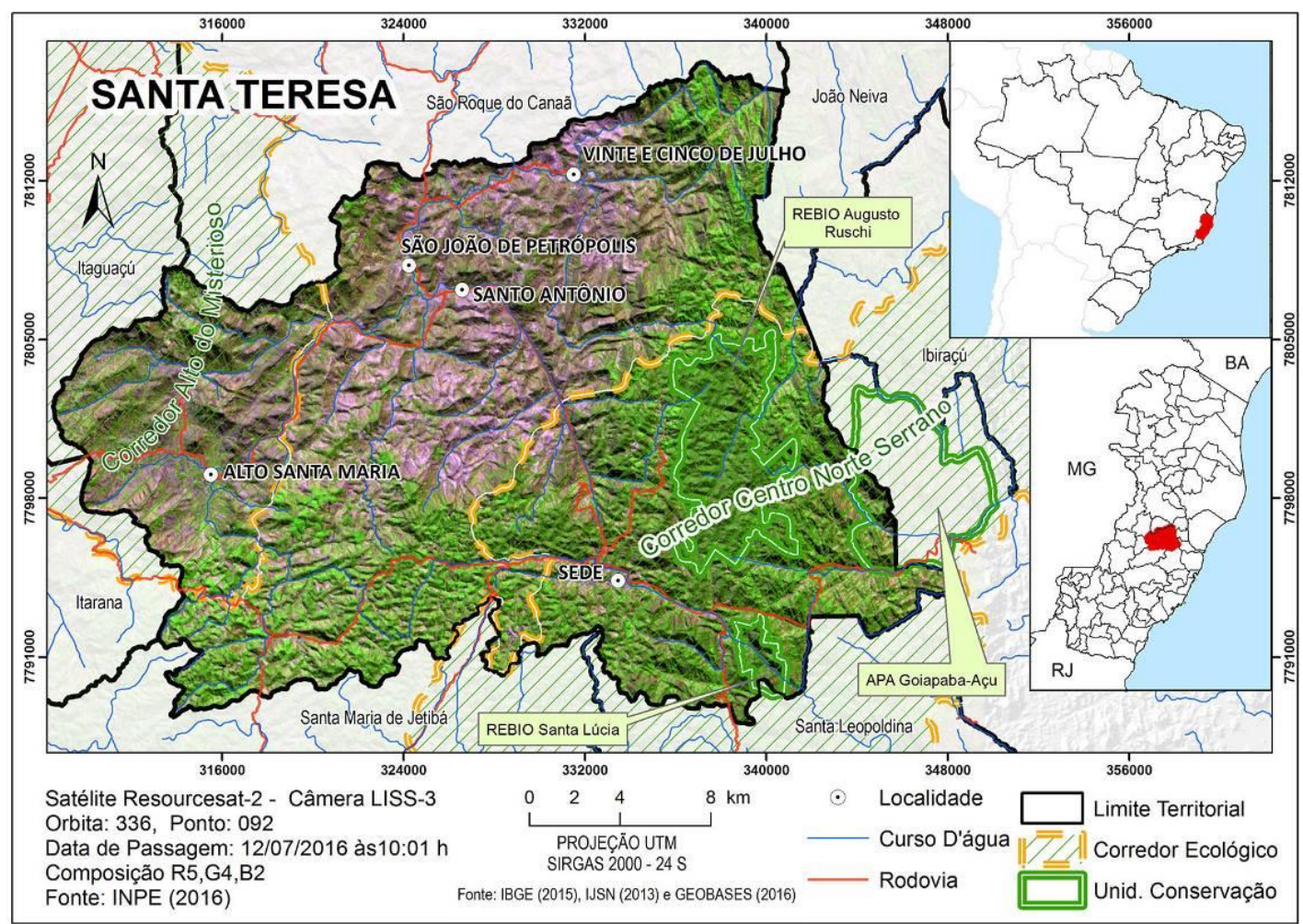

Fonte: Elaborado pelos autores, 2019. 
A paisagem do território é marcada por uma topografia acidentada de estruturas fraturadas constituídas por afloramentos rochosos compostos por três principais unidades geomorfológicas: Patamares Escalonados do Sul Capixaba, abrangendo 74,3\%, Maciços do Caparaó II, com 24,5\% e o Modelado de Acumulação Fluvial, compreendendo 1,1\% (COELHO et. al. 2012; RADAMBRASIL, 1983). Mais de 40\% da área municipal é coberta por remanescentes de Mata Atlântica (INSTITUTO DE PESQUISAS DA MATA ATLÂNTICA, 2005) presentes, sobretudo, a leste e ao sul do território em que estão situadas as Unidades de Conservação - UCs como a Reserva Biológica Augusto Ruschi (3.604 ha), Reserva Biológica de Santa Lúcia (468 ha) e parte da APA Goiapaba-Açu (3.525 ha). Essas UCs compõem um dos principais corredores ecológicos ${ }^{2}$ do estado do Espírito Santo (Figura 1), o corredor Centro Norte Serrano que conta com a maior concentração de cobertura florestal conservada do estado, áreas potenciais de conexão a outras UC's e vocação para implantação de Reserva Particular do Patrimônio Natural - RPPN (PROJETO CORREDORES ECOLÓGICOS, 2006). O oeste do município também é cortado por outro importante corredor ecológico, o Ato do Misterioso, abrangendo a parte sudoeste do vale do Canaã.

Os meses de novembro a março correspondem aos mais chuvosos, com médias superiores a 110 milímetros, enquanto abril a outubro são marcados por períodos de estiagens com o mês de junho, o mais seco, registrando média de $38 \mathrm{~mm}$ (AGÊNCIA NACIONAL DAS ÁGUAS, 2018). Já as temperaturas mínimas variam entre $9,4^{\circ} \mathrm{C}$ e $11,8^{\circ} \mathrm{C}$ e as máximas entre $27,8^{\circ} \mathrm{C}$ e $30,7^{\circ} \mathrm{C}$ (INSTITUTO CAPIXABA DE PESQUISA, 2017).

\section{Metodologia}

Para que os objetivos fossem alcançados, o estudo foi dividido em duas principais etapas, iniciando com compilação do referencial bibliográfico sobre o assunto. A segunda

\footnotetext{
${ }^{2}$ Os Corredores Ecológicos são considerados atualmente uma das principais estratégias de conservação da biodiversidade em todo o mundo. O objetivo é reduzir a fragmentação dos remanescentes florestais, através do aumento da conectividade entre eles, favorecendo o deslocamento de animais e a disseminação de sementes, contribuindo para o fluxo genético entre diferentes populações (INSTITUTO DE PESQUISAS DA MATA ATLÂNTICA, 2005).
} 
etapa foi dedicada à aquisição e tratamento dos planos de informações, conforme Tabela

1.

Tabela 1 - Base de Dados Geoespaciais / Planos de Informações utilizados

\begin{tabular}{|c|c|c|c|c|}
\hline Dado & Tema & Fonte & Ano & $\begin{array}{c}\text { Escala / } \\
\text { Resolução }\end{array}$ \\
\hline UFs & Limite Estadual & IBGE & 2015 & $1: 100.000$ \\
\hline Limite Municipal & Município & IJSN/CGEO & 2013 & $1: 1.000$ \\
\hline UCs & Unidades de Conservação & IJSN/CGEO & 2013 & $1: 1.000$ \\
\hline Corredor Ecológico & Corredor Ecológico & IJSN/CGEO & 2013 & $1: 1.000$ \\
\hline Uso e Cobertura & Uso da Terra & IJSN/CGEO & 2013 & $1: 100.000$ \\
\hline Eixo Viário & Estradas & IJSN/CGEO & 2013 & $1: 100.000$ \\
\hline Área Urbana & Área Urbana & IJSN/CGEO & 2013 & $1: 100.000$ \\
\hline Precipitação & Precipitação Média Anual & ANA & 2018 & $1: 1.000$ \\
\hline Resourcesat-2 & Bandas 2,4 e 5 & INPE & 2016 & 23,5 metros \\
\hline Landsat-8 - TIRS & Banda - 10 & USGS & 2015 & 30 metros \\
\hline Aster-GDEM & Modelo Digital de Elevação & USGS & 2011 & 30 metros \\
\hline Queimada/Incêndio & Focos de Calor & INPE & 2018 & 1,1 km \\
\hline
\end{tabular}

Os principais produtos de sensoriamento remoto adquiridos foram os dados do modelo digital de elevação ASTER/GDEM - (Advanced Spaceborne Thermal Emission and Reflection Radiometer / Global Digital Elevation Model) de resolução espacial $30 \times 30$ metros (UNITED STATES GEOLOGICAL SURVEY, 2011); dados de focos de queimadas reprocessados em Junho $/ 2018^{3}$ com atualizações no número de detecções e localização, com as coordenadas de latitude e longitude, junto ao Portal do Programa Queimadas do Instituto Nacional de Pesquisas Espaciais (INSTITUTO NACIONAL DE PESQUISAS ESPACIAIS, 2018), entre 01 janeiro de 2007 e 31 de dezembro de 2017; imagens de satélite Resourcesat-2, sensor LISS-3, órbita 336, ponto 092, com data de passagem 12/07/2016 e horário central 10h01, bandas: 2, 4 e 5 com resolução espacial de 23,5 metros (INSTITUTO NACIONAL DE PESQUISAS ESPACIAIS, 2016) e banda 10 do satélite Lansat-8, sensor TIRS (Thermal Infrared Sensor), órbita 216, ponto 074, com data de passagem 05/11/2015 e

\footnotetext{
${ }^{3}$ No dia 14 de junho de 2018 o Programa Queimadas do Instituto Nacional de Pesquisas Espaciais (INPE) lançou a nova versão da base de dados de focos de queimadas com atualizações no número de detecções e melhorias na qualidade dos focos e na base cartográfica. Inclui, entre outros aspectos: 1) A correção das detecções dos sensores MODIS (a bordo dos satélites Terra e Aqua) utilizados neste trabalho; 2) Atualização no BDQueimadas de todo o histórico de focos Modis Terra desde 01/Nov/2000 e Aqua desde 04/Jul/2002 para a Collection 6.
} 
horário central 9 h45, com resolução espacial de 30 metros (UNITED STATES GEOLOGICAL SURVEY, 2015).

O processamento dos dados vetoriais e matriciais foi realizado no SIG ArCGIS 10.5 ajustados, quando necessário, no sistema de projeção UTM, Datum SIRGAS-2000, Zona 24 Sul (INSTITUTO BRASILEIRO DE GEOGRAFIA E ESTATÍSTICA, 2005), com todo o mapeamento elaborado seguindo a padronização cartográfica segundo propostas de Fitz (2008); Lo e Yeung (2007); Menezes e Fernandes (2013) e Slocum et. al. (2008) no sentido de desenvolver uma comunicação cartográfica eficiente e objetiva.

O desenvolvimento da cartografia de susceptibilidade a incêndios partiu com a definição das variáveis derivadas dos dados geoespaciais de: 1) uso e cobertura da terra, 2) temperatura de superfície; 3) distância das vias; 4) precipitação e, 5) declividade, seguido do estabelecimento de coeficientes/graus de importância entre 1 a 3, adaptado às características socioambientais do objeto de estudo com o valor 3 relacionado à Alta Susceptibilidade e à definição do tamanho da matriz de 30 × 30 metros, adequados à escala espacial do município.

Já a variável Uso e Cobertura da Terra teve como base o dado geoespacial no formato de vetor Uso da Terra recortado no limite do município - comando Clip, dissolvido nas tipologias de usos - comando Dissolve, seguido da criação de um campo numérico "Peso" na tabela de atributos - comando Create Field e o estabelecimento de coeficientes conforme classes de Usos e Coberturas: Água, Afloramento e Floresta (valor =1); Cultura, Área Urbana e Silvicultura (valor = 2); Pastagem (valor = 3), finalizando com a transformação para matriz a partir do comando Polygon to Raster.

A variável Temperatura de Superfície foi derivada da banda 10 do satélite Landsat8, no período de estiagem, seguido do recorte para o município (comando - Extract by Mask) e aplicação do algoritmo para obtenção da temperatura em graus segundo metodologia de Coelho e Correa (2013) ${ }^{4}$. Em seguida foi realizada a reclassificação com o

\footnotetext{
${ }^{4}$ A aquisição e o tratamento da imagem termal (banda 10) foram estabelecidos conforme critérios: A) Obtenção de imagem 100\% isenta de nuvens e ranhuras; B) Imagem com data de passagem durante o período de estiagem, entre junho a setembro, de maneira a retratar as maiores temperaturas. Na sequência procedeu-se com o recorte abrangendo o objeto de estudo e a aplicação do algoritmo TS= (1321.08/Ln (774.89/(3.3420E-04* "banda10.tif" + 0.10000)+1))-273.15 que calcula os parâmetros fixos de
} 
comando Reclassify, nas seguintes classes e coeficientes: Temperatura $<30^{\circ} \mathrm{C}$ (valor $=1$ ), Temperatura 30 a $35^{\circ} \mathrm{C}($ valor $=2)$ e Temperatura $>36^{\circ} \mathrm{C}($ valor $=3)$.

A variável Distância das Vias teve como base a integração dos dados geoespaciais vetoriais de: Eixo Viário (Valor = 3), área urbana (valor = 2) e Limite Municipal (valor = 1) que foram unidos a partir do comando Union; seguido da dissolução das classes comando Dissolve; transformação para matriz - comando Polygon to Raster e aplicação dos respectivos coeficientes a partir da reclassificação - comando Reclassify.

Já a variável Precipitação partiu dos dados pontuais de média anual da série histórica de pluviometria das estações da ANA, com leituras superiores a 30 anos, distribuídas no município e adjacências seguido do processo de interpolação pelo método IDW - Inverso da Distância ao Quadrado em que as amostras de pontos foram pesadas durante a interpolação de acordo com a influência de um ponto relativo a outro, seguido da reclassificação, através dos comandos - IDW, Extract by Mask e Reclassify, nas seguintes classes e coeficientes: Precipitação < $1.200 \mathrm{~mm} / \mathrm{a}$ (valor = 3), Precipitação entre $1.200-$ a $1350 \mathrm{~mm} / \mathrm{a}($ valor = 2) e Precipitação > $1.350 \mathrm{~mm} / \mathrm{a}($ valor =1).

A variável Declividade teve como base o dado ASTER/GDEM que foi recortado/extraído do limite territorial, gerando a declividade e reclassificado por intermédio da sequência de comandos - Extract by Mask, Slope e Reclassify, nas seguintes classes e coeficientes: Declividades $<=30 \%$ (valor $=1$ ), Declividades 3 a $35 \%$ (valor $=2$ ) e Declividades $>35 \%($ valor $=3)$.

A integração dessas variáveis para a elaboração da cartografia de queimadas e incêndios foi expressa pelo algoritmo matemático: $\mathrm{Cl}=\mathrm{UC} * 35+\mathrm{TS} * 30+\mathrm{DV} * 20+\mathrm{PR} * 10+\mathrm{DC} * 5$ através da ferramenta Raster Calculator. Sendo: $\mathrm{Cl}=$ Cartografia de Incêndios; UC = Uso e Cobertura da Terra (peso 35); TS = Temperatura de Superfície (peso 30); DV = Distância das Vias (peso 20); PR = Precipitação Média Anual (peso 10); e DC = Declividades (peso 5), com os valores representando os pesos atribuídos a cada uma das variáveis. Por fim,

conversão de níveis de cinza da imagem (NC) para radiância, depois para temperatura Kelvin seguido da subtração pelo valor absoluto $(273,15)$, gerando o raster de temperatura de superfície em graus Celsius $\left({ }^{\circ} \mathrm{C}\right)$ no momento da passagem do satélite. 
foram reclassificados (Figura 2) em 3 classes de Susceptibilidades: Baixa, Média e Alta de acordo com a metodologia de Ross (2009).

Figura 2 - Planos de Informações/Variáveis utilizadas na obtenção da cartografia da susceptibilidade a incêndio expresso na equação: $C l=U C * 35+T S * 30+D V * 20+P R * 10+D C * 5$

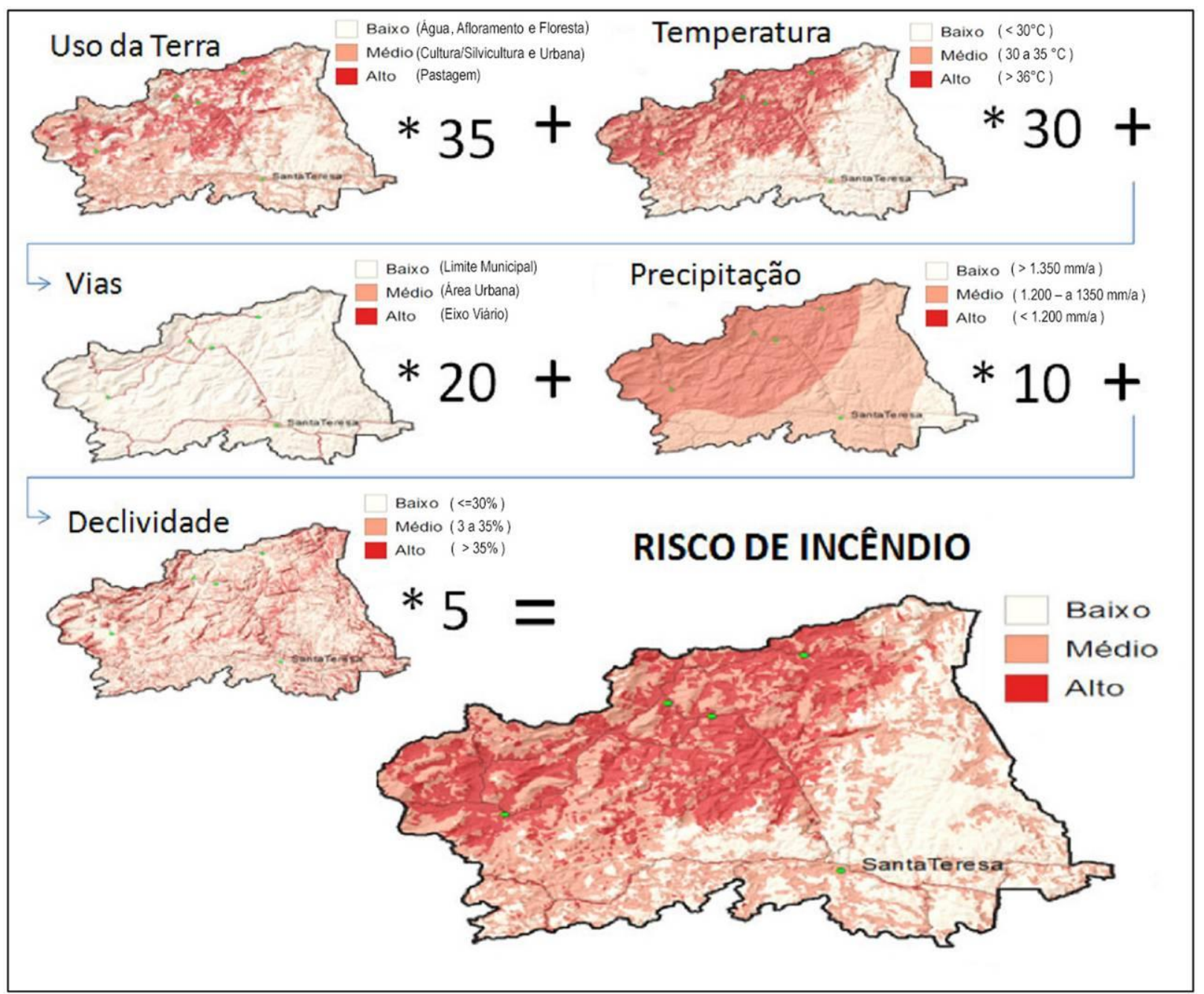

Fonte: Elaborado pelos autores, 2019.

Resumidamente, essa cartografia foi derivada da classificação do registro de cada plano de informação/variável com o estabelecimento de valores/coeficientes entre 1 e 3 na tabela de atributos, conforme o nível de susceptibilidade, finalizada com a atribuição de pesos em cada mapa e somatória ponderada/integração dos mapas. 


\section{Cartografia de incêndios e validação}

A Figura 3 apresenta o Mapa de Susceptibilidade a Queimadas e Incêndios de Santa Teresa (ES) elencando os locais potenciais de ocorrências destacados nas seguintes classes, respectivamente: Baixo (rosa claro), Médio (rosa) e Alto (vermelho escuro).

O produto revelou que a alta susceptibilidade está concentrada nos setores Centro-Oeste e Centro-Norte do território em direção às localidades de Alto Santa Maria ao longo da planície fluvial, em Santo Antônio e Vinte e Cinco de Julho, abrangendo 27,1\% do município (185,07 $\mathrm{km}^{2}$ ), enquanto a média susceptibilidade apresentou o maior percentual com 42,3\% cobrindo uma área de 288,6 km² (Tabela 2), estando distribuída no município porém mais concentrada no setor sudoeste.

Figura 3 - Cartografia da susceptibilidade a queimadas e incêndios

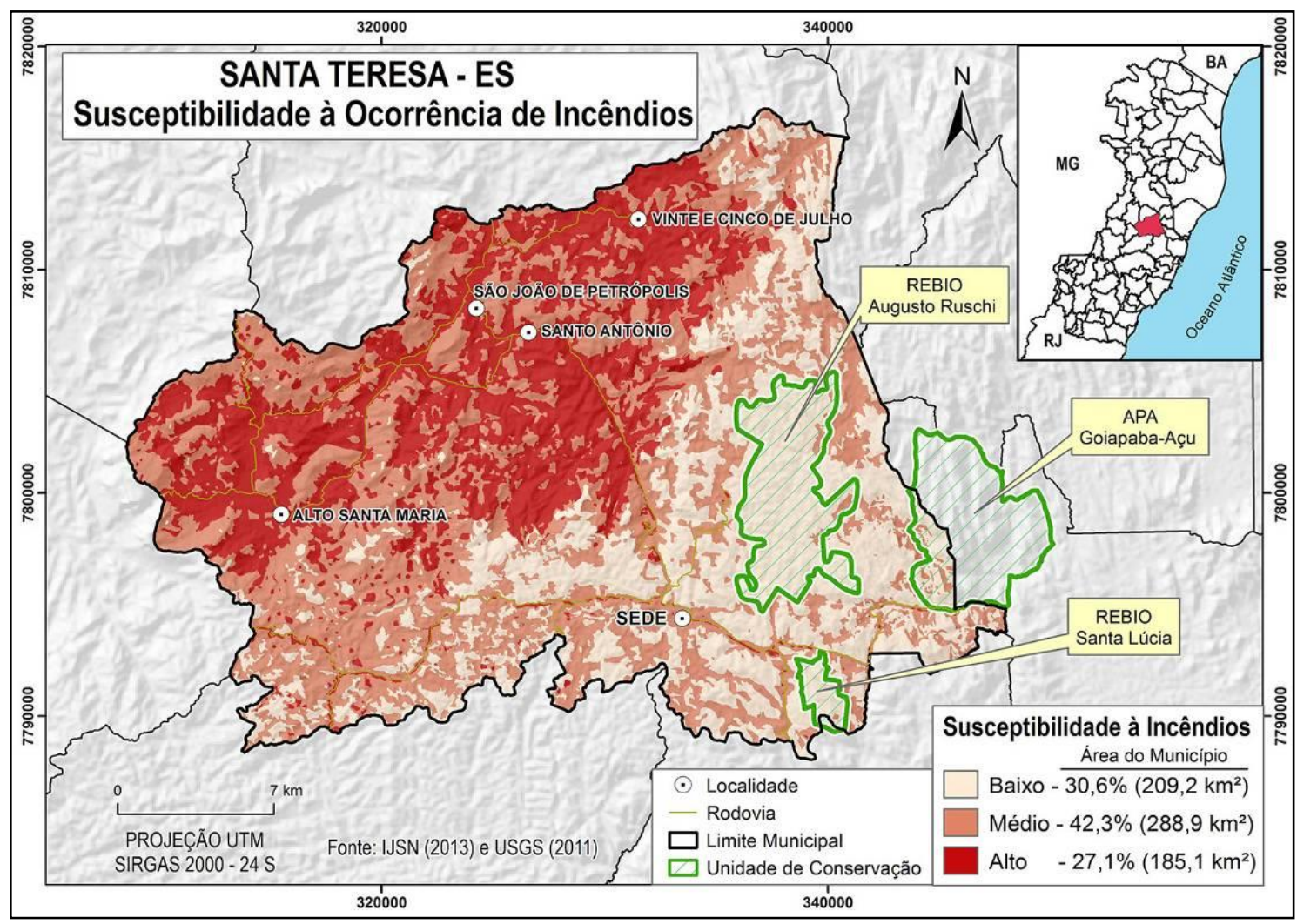

Fonte: Elaborado pelos autores, 2019. 
Tabela 2 - Áreas e Percentuais de Susceptibilidade a Incêndios em Santa Teresa (ES)

\begin{tabular}{|c|c|c|}
\hline $\begin{array}{c}\text { Susceptibilidade a } \\
\text { Incêndios }\end{array}$ & Área $\mathbf{~ k m}^{\mathbf{2}}$ & Percentual (\%) \\
\hline Baixa & $\mathbf{2 0 9 , 1 9}$ & 30,6 \\
\hline Média & 288,85 & 42,3 \\
\hline Alta & 185,07 & 27,1 \\
\hline Totais & $\mathbf{6 8 3 , 1 1}$ & $\mathbf{1 0 0 , 0}$ \\
\hline
\end{tabular}

Já a baixa susceptibilidade a incêndio está mais evidenciada no setor leste, cobrindo 30,6\% do município (209,19 km²), envolvendo as três Unidades de Conservação UCs Reserva Biológica Augusto Ruschi (Figura 4), Reserva Biológica de Santa Lúcia e a APA Goiapaba-Açu, caracterizadas como paisagens em que predominam a cobertura da terra constituída por Mata Atlântica conservada em relevo acidentado de difícil acesso e pouco degradada pela atividade humana.

Figura 4 - Porção norte ocidental da Reserva Augusto Ruschi, distrito de Goiapaba-Açu, alto estrutural correspondente à Unidade Geomorfológica Maciço do Caparaó II, residualmente presente no território de Santa Teresa

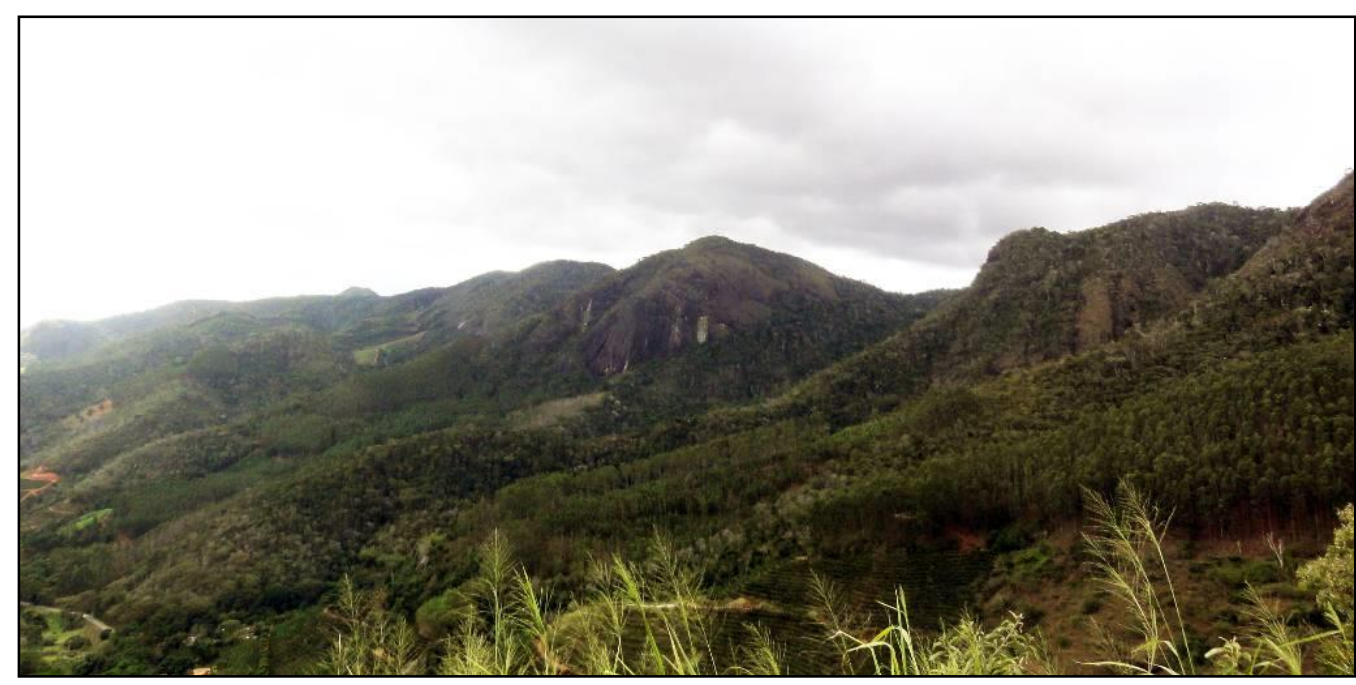

Foto: GOULART, 2017. 
O modelo/cartografia evidenciou também, que a alta incidência de queimada e/ou incêndios está presente no entorno dos eixos viários, sobretudo no setor oeste em direção à localidade de Alto Santa Maria (Figura 5).

Figura 5 - Aspecto geral do vale do alto Santa Maria do Doce (visada a partir do $1^{\circ}$ plano no distrito de Alto Santa Maria em direção ao distrito de Santo Antonio do Canaã. As vertentes marcadas pela lavoura de cultivo sazonal e elevado déficit hídrico

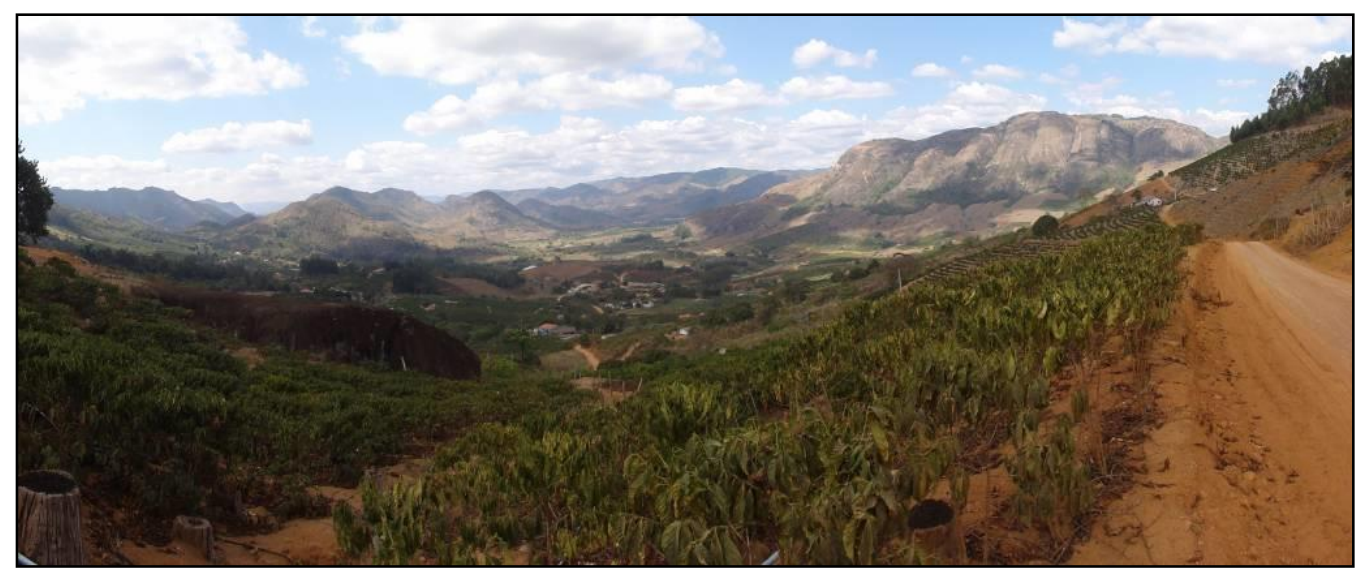

Foto: GOULART, 2017.

\section{Análise dos dados pontuais de focos de calor e validação da cartografia}

Utilizou-se para efeito de validação do produto modelado os registros de focos de calor detectados entre 1/1/2007 e 31/12/2017, reprocessados e disponibilizados em jun/2018 no Portal do Programa Queimadas do Instituto Nacional de Pesquisas Espaciais (INSTITUTO NACIONAL DE PESQUISAS ESPACIAIS, 2018). Os satélites de referência, segundo o INPE, utilizados na detecção de pequenas queimadas e/ou incêndios foram o AQUA_M-T que possui o sensor MODIS - Moderate Resolution Imaging Spectroradiometer e o satélite NOAA-15 com o sensor AVHRR - Advanced Very High Resolution Radiometer.

Ambos são de órbita polar e utilizam em um dos canais/bandas o infravermelho termal ${ }^{5}$ para detecção de frentes de fogo em uma área com cerca de 30 metros de

\footnotetext{
${ }^{5}$ A faixa do espectro eletromagnético que detecta um foco de queimada/incêndio é a termal-média entre 3,7 micrometros a 4,1 micrometros, intervalo atestado em diversas aplicações como Amaral (1992); Coelho e Correa (2013); Jensen (2009); Kazmierczak (2015) e em diversos trabalhos publicados pelo INPE.
} 
extensão por 1 metro de largura ou de maior região queimada ${ }^{6}$. Outras características são apresentadas na Tabela 3.

Tabela 3 - Características dos satélites utilizados que captaram os focos de calor

\begin{tabular}{|c|c|c|c|c|}
\hline $\begin{array}{c}\text { Satélite } \\
\text { Tipo }\end{array}$ & $\begin{array}{c}\text { Tipo de } \\
\text { orbita }\end{array}$ & Sensor & $\begin{array}{c}\text { Resolução } \\
\text { espacial }\end{array}$ & $\begin{array}{c}\text { Resolução } \\
\text { temporal }\end{array}$ \\
\hline AQUA & Polar & $\begin{array}{c}\text { MODIS - Moderate Resolution Imaging } \\
\text { Spectroradiometer }\end{array}$ & $1,0 \mathrm{~km}$ & $2 \times 2 / \mathrm{dia}$ \\
\hline NOAA & Polar & $\begin{array}{c}\text { AVHRR - Advanced Very High Resolution } \\
\text { Radiometer }\end{array}$ & $1,1 \mathrm{~km}$ & $2 \times 2 / \mathrm{dia}$ \\
\hline
\end{tabular}

A Figura 6 expõe o registro anual dos 50 focos de calor detectados pelos sensores MODIS e AVHRR, entre os anos de 2007 a 2017 no município de Santa Teresa (ES), apresentando uma relativa distribuição entre 2007 e 2013, com exceção do ano de 2010, e uma queda nos anos de 2014, 2016 e 2017. Já as maiores concentrações no período, que correspondem a 34\% dos focos, foram nos anos de 2010, com 8 registros, e 2015, com 9 registros, ano de uma das maiores secas ocorridas do estado.

Figura 6 - Distribuição anual dos 50 focos de calor detectados no município de Santa Teresa - ES entre 2007 e 2017 pelos Satélites NOAA-15 e Aqua_M-T. Destaque para os anos de 2010 e 2015 com as maiores ocorrências.

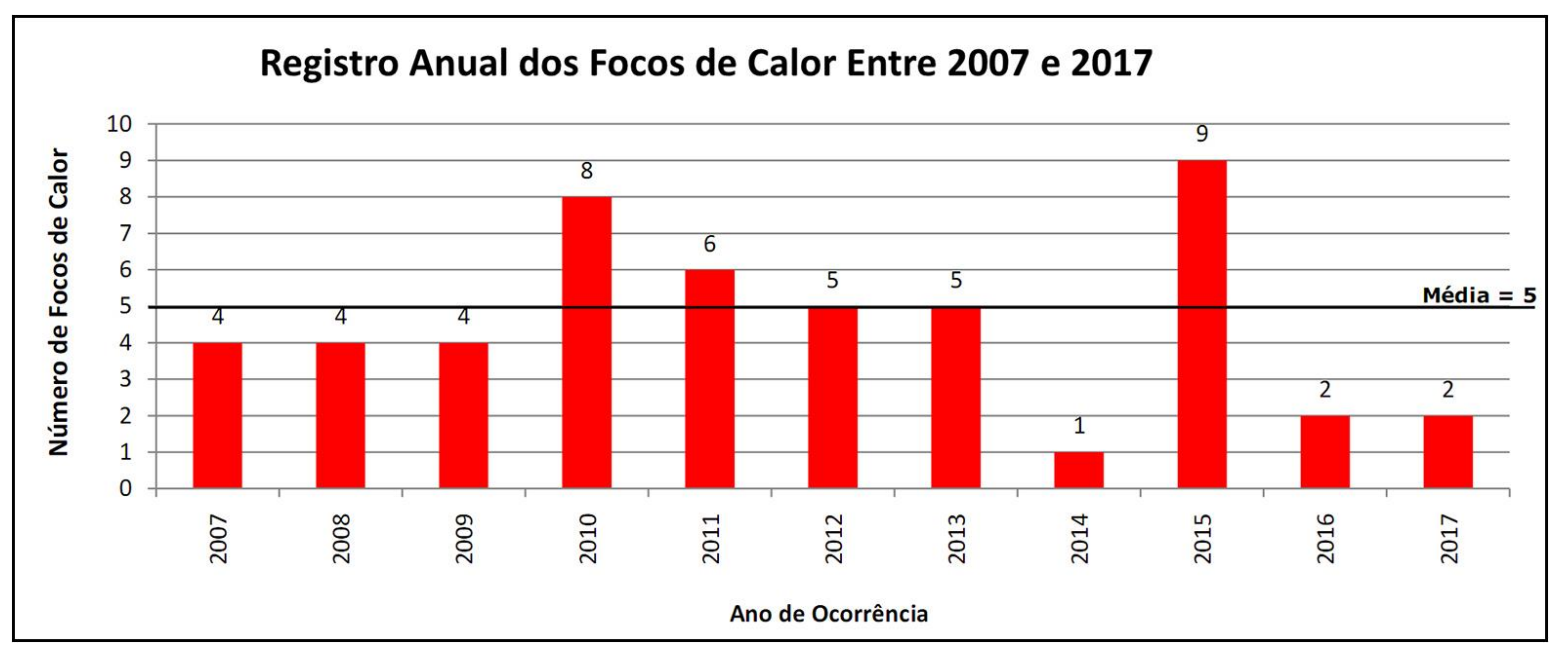

Fonte: Elaborado pelos autores, 2019.

\footnotetext{
${ }^{6}$ Mesmo se uma queimada e/ou incêndio for muito extensa o seu registro no banco dados de incêndios indicará apenas um foco.
} 
Já a análise mensal dos focos de calor detectados pelos sensores no recorte temporal de 2007 a 2017 (Figura 7) revela que os maiores registros estão concentrados nos meses marcados por baixos índices pluviométricos, entre abril e outubro, concentrando $68 \%$ ou 34 das 50 ocorrências no território, sobretudo nos períodos de maior estiagem (setembro e outubro). Nesses meses do ano, o material combustível como capim, galhos e folhas depositados no solo, especialmente nas áreas formadas por pastagens e de baixa concentração de florestas, apresentam elevada susceptibilidade à ocorrência de queimadas e incêndios.

Figura 7 - Distribuição mensal dos 50 focos de calor entre 2007 a 2017.

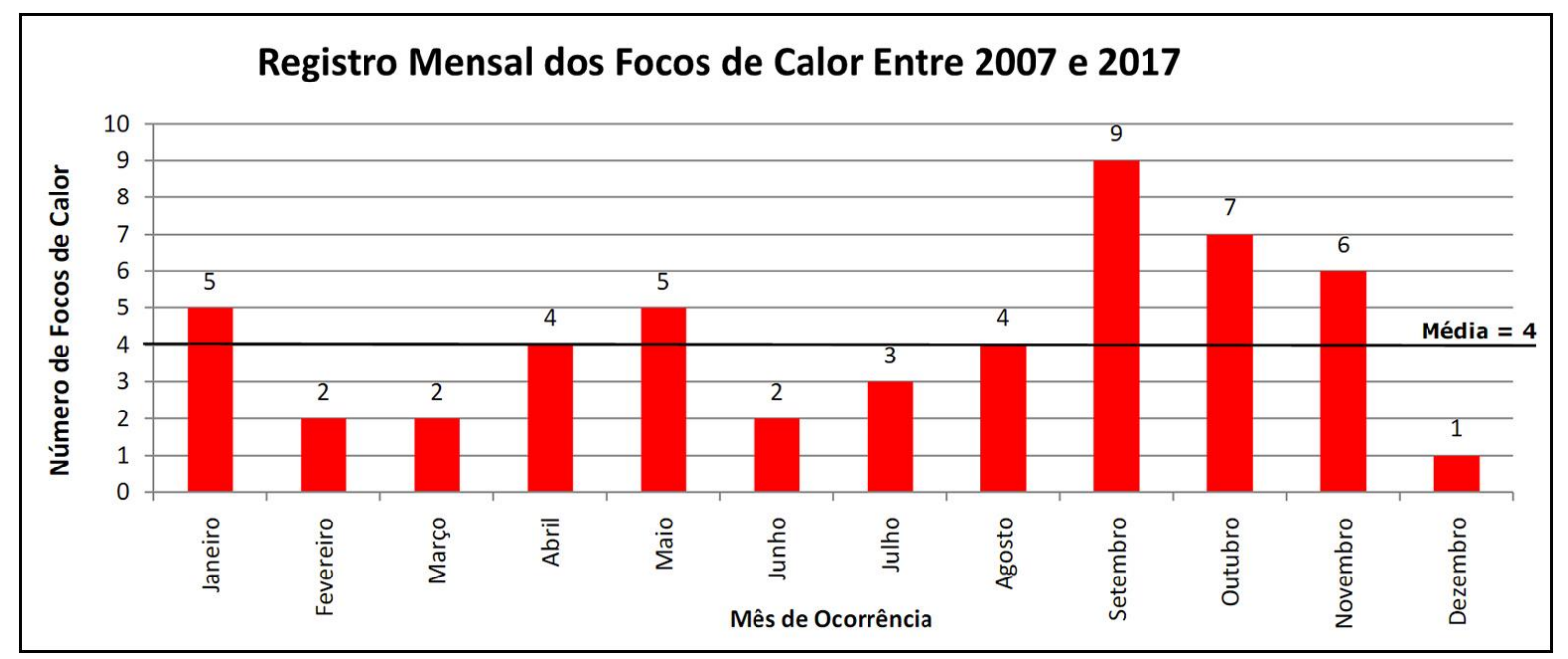

Fonte: Elaborado pelos autores, 2019.

A Figura 8 mostra, em vermelho, a nuvem de pontos dos 50 registros de focos de calor (queimadas e/ou incêndios) detectados pelos sensores MODIS e AVHRR no período de 10 anos no município. 
Figura 8 - Distribuição dos 50 focos de calor detectados por satélites.

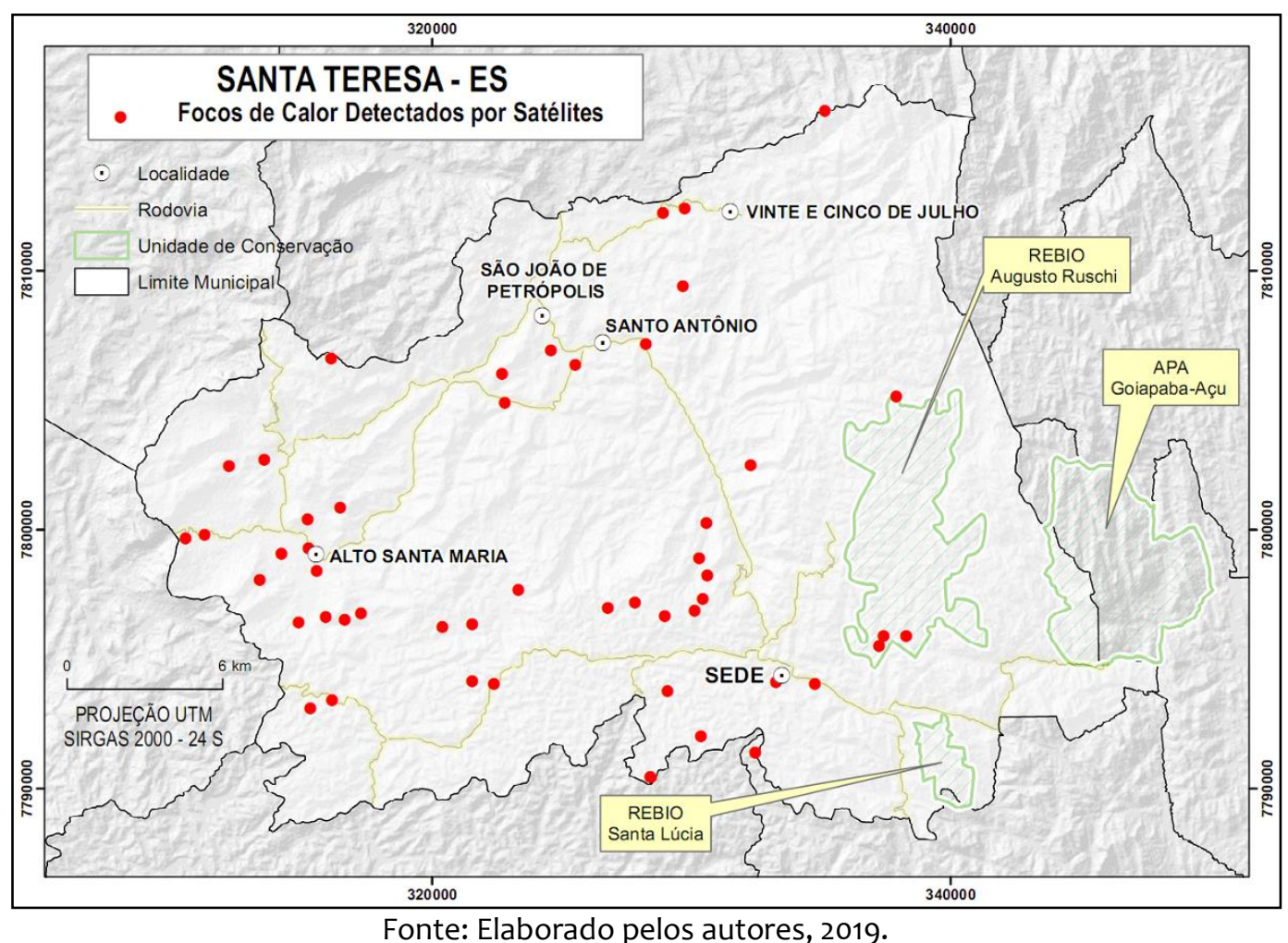

Com base na distribuição espacial dos focos, em ambiente SIG (Figura 8), foi estabelecido o confronto do mapa gerado com procedimento de extração de valores através da função Extract Values to Points, atribuindo para cada um dos 50 pontos, na base de dados geográficos/tabela de atributos, o grau de susceptibilidade a queimadas e incêndios Baixa, Média ou Alta, possibilitando avaliar quantitativamente se a cartografia proposta corresponde, em grande parte dos pontos/focos, às maiores susceptibilidades (Média e Alta).

Dos 50 focos detectados, 31 deles ocorreram em locais de alta susceptibilidade da cartografia gerada, correspondendo a $62 \%$ dos registros. Outro aspecto importante que revela a qualidade do produto modelado são as áreas de alta susceptibilidade que cobrem pequena porção do território, apenas $27,1 \%$, se comparada com as demais áreas analisadas (Figura 9). 
Figura 9 - Cartografia de Susceptibilidade a Incêndio confrontada com os 50 focos de incêndios detectados por satélites em Santa Teresa - ES.

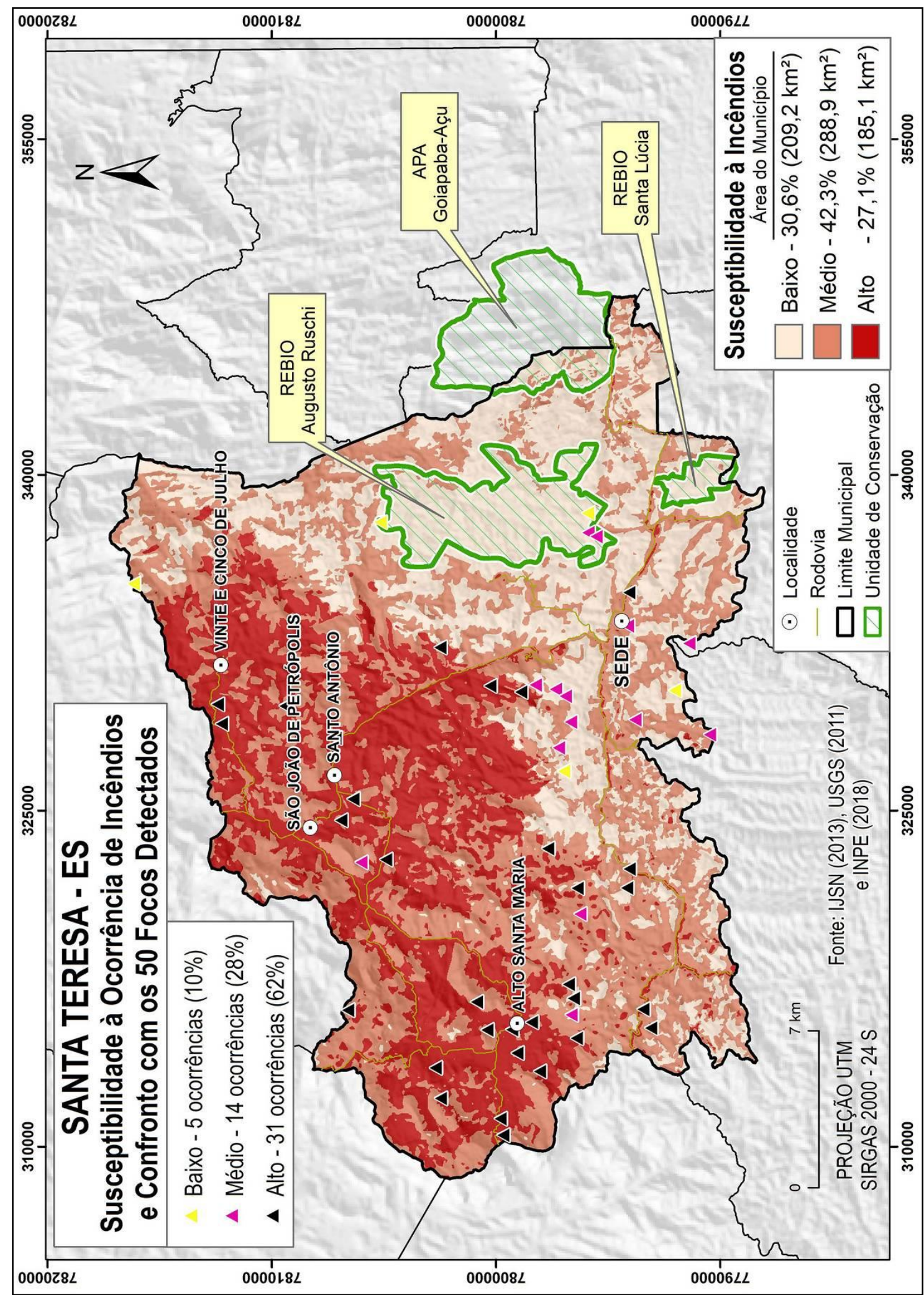

Fonte: Elaborado pelos autores, 2019. 
A análise evidencia também que nas áreas com alta susceptibilidade predominam o uso da terra por pastagens, cultivos agrícolas e áreas de solo exposto, nas proximidades das localidades de Alto Santa Maria, Santo Antônio e Vinte Cinco de Julho. Já os focos em que foram atribuídos os valores de média susceptibilidade estão mais distribuídos no território correspondendo a $28 \%$ dos 50 registros (14 ocorrências), enquanto os de baixa susceptibilidade apresentaram apenas 5 ocorrências (10\%). A análise espacial da distribuição dos pontos/focos de calor e o mapa de incêndios são condizentes revelando que as áreas mais propensas ao fenômeno estão localizadas nos setores centro-oeste e centro-norte.

A utilização das geotecnologias como o SIG e a diversidade de dados, a exemplo de imagens de sensores remotos, como o produto ASTER/GDEM, imagem do Satélite Resourcesat-2, Imagem Landsat-8 termal, planos de informações de Uso e Cobertura da Terra, Eixo Viário, Área Urbana, essenciais para a execução deste trabalho, possibilitaram o cruzamento de variáveis distintas, que se transformaram em informações integradas e que se adaptaram bem à metodologia proposta, tornando possível, ainda, a inclusão de outros planos de informações/variáveis ambientais de altitude, deficiência hídrica e orientação das vertentes.

Sob essa perspectiva, é importante ressaltar que o monitoramento e o conhecimento das áreas de maior susceptibilidade podem servir de base para o direcionamento de ações de contenção e de prevenção dos desastres no Município. Assim, o desenvolvimento da cartografia de incêndios enriquece as pesquisas acadêmicas e os estudos técnicos ao contribuir com a identificação e análise das áreas propensas a esse fenômeno a partir da inter-relação entre os aspectos físico-naturais e a forma de uso da terra pela sociedade.

\section{Conclusões}

A qualidade do Mapeamento de Susceptibilidade a incêndio foi condizente com 90\% dos pontos registrados como focos das ocorrências com índices associados médio e alto detectados pelos sensores MODIS e AVHRR, propondo um produto de baixo custo, 
coerente com a dinâmica de ocorrência de focos de calor no Município. Outro aspecto relevante do mapa proposto, em comparação com as detecções pelos satélites, é que a análise não fica restrita somente aos pontos, como na Figura 8. A cartografia de incêndios elaborada possibilita uma avaliação mais ampla, de todo o território, contribuindo para diversas diretrizes de planejamento e gestão territorial, na ampliação dos inventários de riscos, ao apontar outros locais com alta susceptibilidade, resultando no aumento da eficiência técnica e econômica dos trabalhos de controle e fiscalização.

O produto também pode contribuir para a revisão/elaboração de projetos como o Plano Municipal de Redução de Riscos, além de proporcionar subsídios para análises espaciais, estatísticas e temporais dessas ocorrências e para os estudos dos efeitos ecológicos, atmosféricos e de mudanças climáticas.

O emprego dessa metodologia, associada ao uso das geotecnologias, mostrou-se eficiente após ser comprovado com a base de dados de focos reprocessados e mais precisos do Programa Queimadas do Instituto Nacional de Pesquisas Espaciais (INSTITUTO NACIONAL DE PESQUISAS ESPACIAIS, 2018), oferecendo um produto adicional do qual podem extrair novas informações de locais mais susceptíveis a desastres e, consequentemente, um entendimento mais amplo dos processos que operam nessas paisagens, servindo de base para o direcionamento de ações de redução do risco e a resiliência tanto no meio urbano quanto no meio rural.

Enfim, essa proposta de mapeamento revelou a importância do modelo, para atividades preventivas, possível de ser aplicada em municípios ou regiões carentes de estudos dessa natureza pois a mesma considerou as peculiaridades e particularidades naturais e antrópicas do Município, apontando as restrições para determinados usos das terras em setores do território.

\section{Referências}

AGÊNCIA NACIONAL DAS ÁGUAS. Hidroweb: série histórica de precipitações. Brasília: ANA, 2018. Disponível em: http://www.snirh.gov.br/hidroweb/. Acesso em: 13 ago. 2018. 
AMARAL, Silvana. Imagens do sistema sensor AVHRR/NOAA na detecção e quantificação de desmatamentos: relações com dados do sistema TM/LANDSAT. 1992. Dissertação (mestrado em Sensoriamento Remoto) - Instituto Nacional de Pesquisas Espaciais, São José dos Campos, 1992.

AON BENFIELD. Análise de clima e catástrofes: relatório anual 2017. S.I.: AON BENFIELD, 2018. Disponível em: www.aon.com/portugal/attachments/relatorio-anual-2017-analise-declima-e-catastrofes.pdf. Acesso em: 13 dez. 2018.

BRASIL. Ministério do Desenvolvimento Regional. Secretaria Nacional de Proteção e Defesa Civil. Instrução Normativa MI nº2, de 20 de dezembro de 2016. Estabelece procedimentos e critérios para a decretação de situação de emergência ou estado de calamidade pública pelos Municípios, Estados e pelo Distrito Federal, e para o reconhecimento federal das situações de anormalidade decretadas pelos entes federativos e dá outras providências- anexo V - COBRADE com simbologia. Diário Oficial da União, n. 245, seção1, p. 60. 22 dez. 2016. Disponível em: http://www.mdr.gov.br/defesa-civil/legislacao. Acesso em: 07 jun. 2019.

CANZIAN, Weslen Pintor. Análise de técnicas de combate a incêndios em plantios de eucalipto. 2019. 46 p. Dissertação (Mestrado em Ciências Florestais ) - Programa de Pósgraduação em Ciências Florestais do Centro de Ciências Agrárias, Universidade Federal do Espírito Santo, Jerônimo Monteiro, 2016.

COELHO, Andre Luiz Nascentes. Participação popular na gestão pública: indicação de áreas de interesse ambiental no plano diretor municipal. In: CALDAS, Alcides S.; BRITO, Cristovão; FONSECA A. A. M.; PERTILE, Noeli. (orgs.). Gestão do território e desenvolvimento: novos olhares e tendências. 1. ed. Salvador: JM editora, 2013. p. 275294 .

COELHO, André Luiz. N. Prevenção e mitigação de desastres a partir do mapeamento de fragilidades. In: MAGNONI JÚNIOR, L.; STEVENS, D; LOPES, E. S. S.; CAVARSAN, E. A.; VALE, J. M. F. ; MAGNONI, M. G. M; TEIXEIRA, T.; FIGUEIREDO, W. S. Redução do risco de desastres e a resiliência no meio rural e urbano. São Paulo: Centro Paula Souza, 2017. p. 112-122.

COELHO, André Luiz Nascentes; CORREA, Wesley. Temperatura de superfície celsius do sensor Tirs/Landsat-8: metodologia e aplicações. Revista Geográfica Acadêmica, 2013.

COELHO, André Luiz Nascentes; GOULART, Antonio Celso Oliveira; BERGAMASCHI, Rodrigo Bettim. Mapeamento Geomorfológico do Estado do Espírito Santo. SIMPÓSIO NACIONAL DE GEOMORFOLOGIA, 12. Maringá. Anais [...]. Maringá: SINAGEO, 2012. p. 1-12.

CLIMATE PREDICTION CENTER. El niño/southern oscillation (ENSO). Maryland: CPD, 2018. Disponível em: https://origin.cpc.ncep.noaa.gov/products/precip/CWlink/MJO/ enso.shtml\#history. Acesso em: 5 jun. 2018. 
FITZ, Paulo Roberto. Cartografia básica. São Paulo: Oficina de Textos, 2008.

INSTITUTO BRASILEIRO DE GEOGRAFIA E ESTATÍSTICA (Rio de Janeiro). Estimativas populacionais para os municípios e para as Unidades da Federação brasileiros em 01.07.2018. Rio de Janeiro: IBGE, 2018. Disponível em: www.ibge.gov.br/estatisticasnovoportal/sociais/populacao/9103-estimativas-de-populacao.html. Acesso em 10 set. 2018.

INSTITUTO BRASILEIRO DE GEOGRAFIA E ESTATÍSTICA (Rio de Janeiro). Base de dados geográficos: mapas interativos do IBGE. Rio de Janeiro: IBGE, 2015. Disponível em: ftp://geoftp.ibge.gov.br. Acesso em: 5 jul. 2018.

INSTITUTO BRASILEIRO DE GEOGRAFIA E ESTATÍSTICA (Brasil). Resolução IBGE nº 1/2005. Altera a caracterização do referencial geodésico brasileiro. SIRGAS-2000. Rio de Janeiro: IBGE, 2005. Disponível em:

ftp://geoftp.ibge.gov.br/\%2Fmetodos_e_outros_documentos_de_referencia\%2Fnormas\%2 Frpr_01_25fev2005.pdf. Acesso em: 9 mai. 2018.

Instituto Jones dos Santos Neves / Coordenação de Geoprocessamento - IJSN/CGEO (Espírito Santo). Base de Dados Geográficos. (2013). Disponível em: www.ijsn.es.gov.br/. Acesso em: 5 jul. 2018.

Instituto Capixaba de Pesquisa (Espírito Santo). Assistência Técnica e Extensão Rural. Caracterização climática do município de Santa Teresa (ES). Vitória: Incaper, 2017. Disponível em: http://hidrometeorologia.incaper.es.gov.br/?pagina=carac. Acesso em: 19 jul. 2018.

INSTITUTO NACIONAL DE PESQUISAS ESPACIAIS (Brasil). Catálogo de imagens: imagem satélite Resourcesat-2, sensor LISS-3, órbita 336, ponto 092. São José dos Campos: Inpe, 2016. Data de passagem 12 jul. 2016 e horário central 10:01h, bandas: 2, 4 e 5. Disponível em: www.dgi.inpe.br/catalogo/. Acesso em: 5 jul. 2018.

INSTITUTO NACIONAL DE PESQUISAS ESPACIAIS (Brasil). Portal do programa queimadas do Instituto Nacional de Pesquisas Espaciais: focos de queimadas. São José dos Campos: Inpe, 2018. Disponível em: http://www.inpe.br/queimadas/portal. Acesso em: 16 out. 2018.

INSTITUTO DE PESQUISAS DA MATA ATLÂNTICA (Brasil). Conservação da Mata Atlântica no Estado do Espírito Santo: cobertura florestal e Unidades de Conservação. Vitória: IPEMA, 2005.

JENSEN, John. Sensoriamento remoto do ambiente: uma perspectiva em recursos terrestres. São José dos Campos, SP: Parêntese, 2009. 
KAZMIERCZAK, Marcos Leandro. Sensoriamento remoto para Incêndios florestais. In: SAUSEN,. Tania Maria.; LACRUZ, Maria Silvia Pardi. (orgs). Sensoriamento remoto para desastres. São Paulo: Oficina de textos, 2015. p. 174-211.

LO, Chor Pang, YEUNG, Albert Introduction to geographic information systems (GIS). In: CONCEPTS AND TECHNIQUES OF GEOGRAPHIC INFORMATION SYSTEMS. 2nd ed. [S.I.: s.n.], 2007. (Ph. Series in Geographic Information Science)

MENDONÇA, Francisco.; DANNI-OLIVEIRA, Inês Moresco. Climatologia: noções básicas e climas do Brasil. São Paulo: Oficina de Texto, 2007.

MENEZES, Paulo Marcio Leal.; FERNANDES, Manoel do Couto. Roteiro de cartografia. São Paulo: Oficina de Textos, 2013.

INSTITUTO ESTADUAL DE MEIO AMBIENTE E RECURSOS HÍDRICOS. (Espírito Santo). Projeto Corredores Ecológicos: síntese do processo de definição e planejamento dos corredores prioritários no Espírito Santo. Projeto Corredores Ecológicos.Cariacica, 2006.

RADAMBRASIL. Levantamento de recursos naturais: geologia, geomorfologia, solos, vegetação e uso potencial da terra: volume 32, Folhas SF 23/24. Rio de Janeiro IBGE; Brasília: Ministério das minas e energia, Secretaria Geral, 1983. 775 p.

ROSS, Jurandir Luciano Sanchez. Paisagem, configuração territorial e espaço total: interação da sociedade com a natureza. In: ECOGEOGRAFIA DO BRASIL: subsídios para planejamento ambiental. São Paulo: Oficina de Textos, 2009. p. 47-61.

SECRETARIA NACIONAL DE PROTEÇÃO E DEFESA CIVIL. Manual de desastres naturais: Volume I. Brasília: Secretaria Nacional de Proteção e Defesa Civil, 2003. Disponível em: www.integracao.gov.br/c/document_library/get_file?uuid=47a84296-d5co-474d-a6ca8201e6c253f4\&groupld=10157. Acesso em: 10 dez. 2018.

SLOCUM, Terry et al. Thematic cartography and geovisualization. 3rd ed. [S.I.: s.n.], 2008. (Ph. Series in Geographic Information Science)

UNITED STATES GEOLOGICAL SURVEY. Dados de altitude ASTER/GDEM: advanced spaceborne thermal emission and reflection radiometer/global digital elevation model. Id.: ASTGDEMV2_oS20W041. Data de passagem 17 out. 2011. Disponível em: http://earthexplorer.usgs.gov. Acesso em: 06 abr. 2018.

UNITED STATES GEOLOGICAL SURVEY. Imagem landsat-8: banda 10, sensor TIRS thermal infrared sensor. Data de passagem 05 nov. 2015. Disponível em: http://earthexplorer.usgs.gov. 06 abr. 2018. 
VALLEJO, Luiz Renato. Os focos de calor e os incêndios em unidades de conservação brasileiras no ano de 2010. In: BARBOSA. J. L.; LIMONAD, E. (orgs). Ordenamento territorial e ambiental. Niterói, RJ: Editora da UFF, 2012. p. 265-281.

Recebido em: 31/01/2019 Aprovado em: 30/09/2019

Universidade do Estado de Santa Catarina - UDESC Centro de Ciências Humanas e da Educação - FAED Revista PerCursos Volume 20 - Número 43 - Ano 2019 revistapercursos@gmail.com 